\title{
Concrete casting robustness improvement due to active rheology
}

\author{
Wolfram Schmidt, Hans-Carsten Kühne, Sarah Leinitz \\ Bundesanstalt für Materialforschung und -prüfung (BAM), Department „Safety of Structures“, Berlin, Grmany
}

\begin{abstract}
With ongoing innovation in process technology, the challenges of concrete technology are more and more focused on the rheological optimisation for these processes, since improper mixture stability or poor compaction ability negatively affect the concrete homogeneity and quality. However, along with the increasing complexity of today's concrete mixture compositions, concrete becomes more prone to failure regarding the casting process. Variable properties of the raw materials typically cause changing workability. The reasons can be found among others in scattering water contents, physical or chemical properties of the cement or varying environmental temperatures. Robustness in the delicately adjusted rheology, however, is of utmost importance for modern and future process technology, from sprayed concrete over pumpable concrete towards 3D-printing, with regard to the long-term strength, the function and the durability. Typically, material induced changes cannot be identified easily due to the complex interactions of concrete constituents. Therefore, a precise and prompt counteraction is impossible. However, it is known that the yield stress can be controlled by addition of supplementary superplasticizer or stabilising agent. In combination with computerized process observation tools that can rapidly interpret and react on changes in the rheology, it is therefore thinkable, that only these two admixture types can adjust the rheology steadily and permanently, regardless of the actual root cause for observed macroscopic rheology change. The presentation will firstly give a comprehensive overview of effects at the interface between pore solution, particles and hydrates, which affect the rheology of fresh concrete. Secondly, ways are recommended how the rheology can be actively manipulated before eventually computerized methods are demonstrated that help to actively and rapidly assess and counteract performance scatter during steady casting processes.
\end{abstract}

\section{State of the art}

\subsection{Relevance of robust rheology and effective process control}

Concrete construction today has become more sophisticated, innovative, future oriented, and performance based. Compared to the past, where cement, water, and aggregates were major components, today supplementary additions and chemical admixtures have become important. Admixtures eventually facilitated the development of new concrete types such as selfcompacting concrete, high performance concrete, strain hardening cement-based composites and a variety of special mortars and concrete types by uncoupling the workability from the water-cement ratio $(w / c)$.

The price for the technological potentials are more sensitive systems that are prone to failure, particularly in terms of the rheological properties. Future additive automated process technologies will further increase the demands on the rheology of concrete. Table 1 provides an overview of some recent and future technologies and the specific rheological challenges that lie within.
Table 1. Rheological challenges for different concrete manufacturing technologies.

\begin{tabular}{|c|c|}
\hline $\begin{array}{c}\text { Manufacturing } \\
\text { technology }\end{array}$ & $\begin{array}{c}\text { Rheological challenge with relevance for } \\
\text { unction, safety and durability }\end{array}$ \\
\hline $\begin{array}{l}\text { 3D-printing of } \\
\text { concrete elements }\end{array}$ & $\begin{array}{c}\text { In-situ measurement of the workability and } \\
\text { in-situ counter control required }\end{array}$ \\
\hline $\begin{array}{l}\text { Self-compacting } \\
\text { concrete }\end{array}$ & $\begin{array}{c}\text { Effective avoidance of segregation and } \\
\text { stagnation }\end{array}$ \\
\hline $\begin{array}{l}\text { Ready-mixed } \\
\text { concrete }\end{array}$ & $\begin{array}{c}\text { Good workability properties despite } \\
\text { transport delays }\end{array}$ \\
\hline \begin{tabular}{|c|} 
Grouting, esp. \\
Offshore-Grouting \\
\end{tabular} & $\begin{array}{l}\text { Better consistency to avoid blockages in } \\
\text { pipes which lead to technical problems }\end{array}$ \\
\hline Pumping concrete & $\begin{array}{l}\text { Optimised rheology can save energy costs } \\
\text { and increase pumping height }\end{array}$ \\
\hline $\begin{array}{c}\text { Fibre } \\
\text { concrete/SHCC }\end{array}$ & $\begin{array}{c}\text { Differences in the rheology of pastes can } \\
\text { cause poor fibre distribution and } \\
\text { agglomeration of fibres }\end{array}$ \\
\hline Sprayed & $\begin{array}{l}\text { Small changes to the water/additive content } \\
\text { influences rebound and run out }\end{array}$ \\
\hline
\end{tabular}

Today, a variety of binders are used from ordinary Portland cement (OPC) to largely calcium free geopolymers and everything in between. At the same time, modern construction chemicals found their way into 
concrete daily routine, which, however, often react sensitive towards changes in the environmental conditions as well as scatter in the quality of raw materials. These parameters were relevant already in the past with normal concrete but they could be compensated typically by increased compaction effort, and in addition the expectations on the performance were lower. For many high performance modern concrete types and particularly those that will come up in future in conjunction with additive manufacturing, the rheological performance is crucial for the manufacturing process, the function of the concrete as well as eventually the durability. The higher complexity of binders, admixtures and additions is hence a thread to high performance concrete technology and automated processing. Hence, robust rheology is the key challenge of the future, but maintaining a permanent rheology without large scatter is difficult to achieve in daily practice since:

- Due to the complexity of concrete, which is a multiple scale $(\mathrm{nm}$ to $\mathrm{cm}$ ), multiple phase (various organic and inorganic components), and time-dependent system, the root cause for changing and scattering rheology performance is difficult to find. E.g. changes can be induced by the water absorbed by aggregates, the gypsum in the cement, the fineness of the powder constituents, variations in the particle size distribution, and many more.

- Rheology affecting influences can be induced uniquely or systematically. Upon occurrence of a rheology change in concrete production, it is difficult to assess rapidly whether a change is systematic or has just happen within the normal range of scatter.

- When counteractions against unwanted rheology are identified (e.g. more or reduced superplasticizer) it is still difficult to find the relevant dosage without overshooting the target. This is aggravated by the complexity of the system and the typically unknown root cause for scatter and deviation.

\subsection{Process control and decision making methods}

Due to the relevance of robust rheology, particularly in automated processing, process observation and control tools are getting more and more relevant in the future. In production control, most of the time people observe process values (e.g. in concrete technology this would be compressive strength, air pore content or density). In order to better assess process data, control charts were developed, where the process data are plotted over the course of time and often compared to indicator values. The objective is a steady production with regard to the observed process value and as low as possible scatter around a target value. Largely known and well established are so called Shewhart charts, which were developed in the 1920 s by W.A. Shewhart [1]. The relevant process values are plotted consecutively in comparison to a deviation of the twofold and threefold standard deviation. In case the twofold standard deviation line is touched by the process values it indicates that the process is at risk to run out of control, and corrective actions should possibly be taken, but still the process is within the $95 \%$ confidence interval. A crossing of the threefold standard deviation line indicates that the process significantly runs out of control. Counteractions have to be taken instantly to bring the process back into control. However, Shewhart charts react quickly on dramatic and instant changes of a process, but they react relatively slowly on smaller but systematic process deviations. In order to identify a process deviation. Small systematic changes cannot be detected at all by Shewhart charts. A user has to observe the chart for a long period of time to identify the changed production, so that counteractions can only be taken after a long period of time. In order to have a more efficient tool that helps to react quicker on systematic changes in processes, Cusum control charts were developed in the 1950 s by E. S. Page $[2,3]$. Cusum stands for "cumulative sum".

Cusum charts look at the deviations from a target value. Cusum charts react more rapidly on systematic changes in processes than other charts such as Shewhart charts, which look at the process values. It has been used in various fields successfully, e.g.

- As a learning curve for the evaluation of different medical treatments, anaesthesia, or intubation [4-7]

- Documentation of the complication rates occurred in chirurgical practice and competence assessment [8]

- Evaluation of patient data with regard to laboratory errors and more rapid error identification [9]

- For the improvement of the predictability of chirurgical protocols [10]

- Surveillance and evaluation of fish stocks and balances without and with little historic data information $[11,12]$

- For the monitoring of production events [13]

A cusum can be derived according to the equation:

$C(n)=\Sigma\left(A_{i}-A_{\text {target }}\right)$

Where: $\mathrm{C}(\mathrm{n})=$ cusum function; $\mathrm{A}_{\mathrm{i}}=$ last process value; $A_{\text {target }}=$ target value

Hence, instead of observing process values, cusum shows trends in the deviations from the target value and the following conclusions can be made based on eq. (1):

- An upward trend indicates that real process values are higher than the targeted value. This is often an indicator for uneconomic processes and should be a trigger for measures that help reducing the production costs (e.g. products are too thick $\rightarrow$ material can be saved; or strength is higher than required $\rightarrow$ cement can be saved).

- A horizontal trend indicates that the process runs as expected and no changes in the process or mixture composition should be made.

- A downward trend indicates that the real process values are lower than the targeted value. This is often an indicator for production that is technically not appropriate (products are too thin $\rightarrow$ more material is needed to fulfil the technical specifications; or strength too low $\rightarrow$ more cement required). 
Table 2. Sample for cusum calculation.

\begin{tabular}{|c|c|c|c|c|}
\hline & $\begin{array}{c}\text { Target value } \\
\mathrm{f}_{\mathrm{cta}}=45.0 \\
\end{array}$ & $\begin{array}{c}\text { Production } \\
\text { data }\end{array}$ & \begin{tabular}{c|c|} 
Target \\
deviation
\end{tabular} & Cusum \\
\hline & \multicolumn{4}{|c|}{ [MPa] } \\
\hline & $\begin{array}{c}\text { Seq. } \\
\text { Number }\end{array}$ & $\mathrm{f}_{\mathrm{ci}}$ & $\mathrm{f}_{\mathrm{ci}}-\mathrm{f}_{\mathrm{cta}}$ & $\Sigma\left(\mathrm{f}_{\mathrm{ci}}-\mathrm{f}_{\mathrm{cta}}\right)$ \\
\hline \multirow{7}{*}{$\begin{array}{l}\text { Production } \\
\text { below target } \\
\text { value }\end{array}$} & 1 & 40.1 & -4.9 & -4.9 \\
\hline & 2 & 45.0 & 0.0 & -4.9 \\
\hline & 3 & 41.1 & -3.9 & -8.8 \\
\hline & 4 & 41.9 & -3.1 & -11.9 \\
\hline & 5 & 42.1 & -2.9 & -14.8 \\
\hline & 6 & 43.5 & -1.5 & -16.3 \\
\hline & 7 & 42.2 & -2.8 & -19.0 \\
\hline \multirow{6}{*}{$\begin{array}{l}\text { Production } \\
\text { according to } \\
\text { plan }\end{array}$} & 8 & 43.1 & -1.9 & -20.9 \\
\hline & 9 & 48.3 & 3.3 & -17.7 \\
\hline & 10 & 41.5 & -3.5 & -21.2 \\
\hline & 11 & 47.3 & 2.3 & -18.9 \\
\hline & 12 & 45.4 & 0.4 & -18.5 \\
\hline & 13 & 46.2 & 1.2 & -17.3 \\
\hline \multirow{7}{*}{$\begin{array}{l}\text { Production } \\
\text { above target } \\
\text { value }\end{array}$} & 14 & 47.5 & 2.5 & -14.8 \\
\hline & 15 & 48.5 & 3.5 & -11.3 \\
\hline & 16 & 45.5 & 0.5 & -10.8 \\
\hline & 17 & 44.6 & -0.4 & -11.2 \\
\hline & 18 & 44.2 & -0.8 & -12.0 \\
\hline & 19 & 47.2 & 2.2 & -9.8 \\
\hline & 20 & 48.1 & 3.1 & -6.7 \\
\hline
\end{tabular}
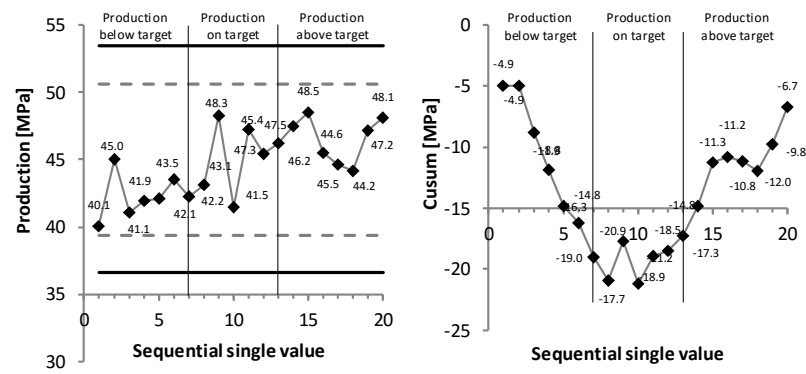

Fig. 1. Control charts for data from Table 2; left: sample shewhard chart with control lines at twofold (dashed) and threefold (full line) $\sigma$; right: respective cusum chart.

Error! Reference source not found. show a cusum calculation example with the respective data plot as a Shewhart-chart (left) and as a cusum chart (right). While the Shewhart chart cannot clearly indicate systematic process changes, the cusum plot indicates the values below target (1-7) directly by a downwards trend, and the values above target (14-20) by a steep increasing slope.

Although the cusum delivers a vivid picture of process deviations, it remains difficult to assess quickly, whether corrective actions are required or not. An effective process control should avoid under-control by indicating deviating processes as early as possible to minimise defective production, but it should also avoid over-control, where counteractions are taken although the process deviates within normal scattering ranges. Hence, decision making is always a compromise between overcontrol and under-control.

A so called V-mask helps to assess whether trending curves show critical trends or not [14-16]. It ideally provides very clear decision rules whether counteractions must be taken or not. V-masks are composed of $\mathrm{V}$-shaped decision lines and a decision interval (DI) that can be superimposed retroactively on the cusum curve. No intervention is necessary as long as the cusum curve is located within the area delineated by the limbs of the V-mask (decision lines). As soon as a decision line is intersected this clearly indicates that immediate corrective actions are required. DI, slope of the decision line (SL), and observation interval form a unit and should be adjusted to the process according to the following considerations:

- The decision interval determines the reliability of the detection.

- The slope of the decision line determines the size of change to be detected.

- The observation interval should be appropriate for the process.

\subsection{Cusum process control in concrete technology}

In concrete technology, the use of cusum has become popular for the quality control in the UK, South Africa, and Australia [18-23]. In other countries, it is not well established. It has mostly been applied for strength observation, but also as multi-parameter method for e.g. air content and concrete temperature.

Cusum in combination with a V-mask evaluation has also entered the European standards recently since it has been approved to become a method to assess the conformity of the compressive strength in EN 206 as an alternative for the existing mean value criterion. However, cusum was fundamentally developed for process control and not for conformity control, which follows different objectives. The conformity is regulative, has to be observed by third parties, and counteractions in case of non-conformity are mandatory, but not required before the conformity is at risk. The process optimization is not mandatory, but lies within the interest of the producer to produce cost efficient and technologically satisfying. Corrective actions should be taken as early as possible in the interest of the producer. Caspeele and Taerwe proved that depending upon the parameters of the $\mathrm{V}$-mask both conformity control and quality control can be achieved, but a tailoring of the V-mask to the production target value is required [16]. However, these recommendations were not considered in EN 206, so that the recommended standard method of EN 206 is not a feasible tool for process optimization [14, 24].

\subsection{Cusum process control for robust rheology}

Cusum cannot only be used effectively for conformity control but it can be a viable option for process control. For the concrete production, it has not been used to date. It has largely been applied for mechanical properties of concrete, but strength relevant data typically occur only after a while, so that the strength of the cusum method to react rapidly on systematic changes cannot be efficiently used, even when predictive early strength values are applied.

The strength of cusum is its capacity to identify systematic process changes very rapidly. Therefore, the 
system is an ideal candidate for the process control and robustness enhancement of the rheology of concrete much more than for any other concrete property.

The V-mask for cusum can deliver very clear decision lines for the deviation of the slump flow, the Vfunnel time, the yield stress, the plastic viscosity, or any other value related to rheology, depending upon the available equipment. However, once the V-mask indicates counteractions, they need to be taken effectively. Ideally, there should be only two options one possible counteraction per limb of the V-mask.

\subsection{Challenges for decision making}

The major challenge for the application of a cusum in concrete technology lies in identifying counter actions for changed rheological properties. In concrete, the root causes for process deviations can be vast, and similarly vast can be the possible counteractions. The rheology of concrete can be affected by a vast variety of parameters. With increasing complexity of cementitious binders and considering the complex interaction between cement and rheology modifying admixtures on the micro scale [2534] the variety of possible rheology changing influences is becoming significantly worse.

Practically this means, segregation can be effectively counteracted among many others by alternatively reducing the water volume in the mix, by increasing the specific surface of the sand, by changing the cement type, by varying the superplasticizer (SP), by adding stabilising agent (STA) or fines, or many other options.

Hence, cusum process control can only effectively work with regard to rapid rheology adjustment, in case very clear and effective counteractions can be defined. Due to the complexity of the overall system, the corrective actions need to be strong rheology modifiers with a good performance predictive capacity. Their effect has to manipulate the rheology of the concrete regardless of the root cause. Due to their strong effect on the flowability, superplasticizers based on polycarboxylate ethers (PCE) and polysaccharide stabilising agents could be potential agents to actively control the rheology and to re-adjust the flowability target value when scatter in the constituents occurs. This study assesses the feasibility of these agents to control the rheology of self-compacting concrete actively by using a cusum control chart in conjunction with $\mathrm{V}$-mask decision making.

\section{Experimental setup}

The objective of the study is to observe whether a cusum evaluation with $\mathrm{V}$-mask can respond quickly on a variety of influences resulting from modified parameters in the mixture composition. In order to obtain realistic values for mean value changes and standard deviations induced by the changes, experiments were conducted with self-compacting mortar. The reference had slump flow (SF) of $237.7 \mathrm{~mm} 15$ minutes after the mixing.

- The following stiffening manipulations were made, each variation of which was observed with $0.00 \%$,
$0.20 \%$ and $0.40 \%$ of supplementary PCE in addition to the reference dosage of $1.8 \%$ PCE. The solid content of the PCE was $30 \%$.

$\circ-10 \%$ water addition

o $+10 \%$ cement

$\circ \quad+10 \%$ limestone filler (LSF)

- The following liquefying manipulations were made, each variation of which was observed with $0.00 \%$, $0.03 \%$ and $0.06 \%$ of ST based on potato starch.:

$$
\begin{array}{ll}
\circ & +10 \% \text { water addition } \\
\circ & -10 \% \text { cement } \\
\circ & -10 \% \text { limestone filler (LSF) }
\end{array}
$$

For all variations arithmetic means (AM) and standard deviations $(\sigma)$ for the normal processes and manipulated processes were determined as well as for the same processes with different dosages of superplasticizers and stabilising agents. Each test was repeated three times for the determination of the $\sigma$ and the AM. This allowed assessing and predicting performances of manipulated SCC systems with and without PCE or ST, as well as of normal SCC systems with overdose of PCE or unnecessary dosage of ST. The data was used to derive linear regression functions to predict the required admixture dosages to bring the deviating SF performance back to the set target SF of $237.7 \mathrm{~mm}$, and to predict the performance of the reference mixture with different admixture dosages.

\section{Statistical data evaluation}

The experimentally derived data were used to generate representative normally distributed random values. The scenario shown in Table 3 was observed for the manipulations described in the experimental setup. The general purpose, standard, truncated V-mask according to BS 5703-2 [17] that was applied every ten values has a DI of $5 \sigma$, an SL of $0.5 \sigma$, and an observation interval of 10 process values.

Table 3. Observed scenarios with 50 production values.

\begin{tabular}{|l|l|l|}
\hline $\begin{array}{l}\text { Prod. } \\
\text { values }\end{array}$ & Situation & Observation target \\
\hline $1-10$ & $\begin{array}{l}\text { Normal } \\
\text { production }\end{array}$ & - \\
\hline $11-20$ & $\begin{array}{l}\text { Defective } \\
\text { production }\end{array}$ & $\begin{array}{l}\text { Can defective production be } \\
\text { identified quickly? }\end{array}$ \\
\hline $21-30$ & $\begin{array}{l}\text { Defective } \\
\text { production }\end{array}$ & $\begin{array}{l}\text { Can PCE or STA bring a defective } \\
\text { production back to target? }\end{array}$ \\
\hline $31-40$ & $\begin{array}{l}\text { Normal } \\
\text { production }\end{array}$ & $\begin{array}{l}\text { Can the return to normal } \\
\text { production be identified? }\end{array}$ \\
\hline $41-50$ & $\begin{array}{l}\text { Normal } \\
\text { production }\end{array}$ & - \\
\hline
\end{tabular}

\subsection{Stiffening effects}

The results of the data analysis for the stiffening effects are shown for exemplary data sets in Figs. 2-4. In all cases, the slope of the cusum changes dramatically, after the first manipulation is applied. The reduction of the SF causes a downward trend, since the production 
values are lower than the target. The limbs of the V-mask are clearly touched, indicating corrective action requirement. After the correction using additional PCE, the cusum trends horizontally again and stays within the limbs of the V-mask until the manipulation is gone but the corrective actions are still taken. This situation can also be clearly identified by a distinct upward slope change of the cusum and by crossing the limbs of the Vmask. After the no longer required corrective actions are stopped, the cusum runs horizontally again.

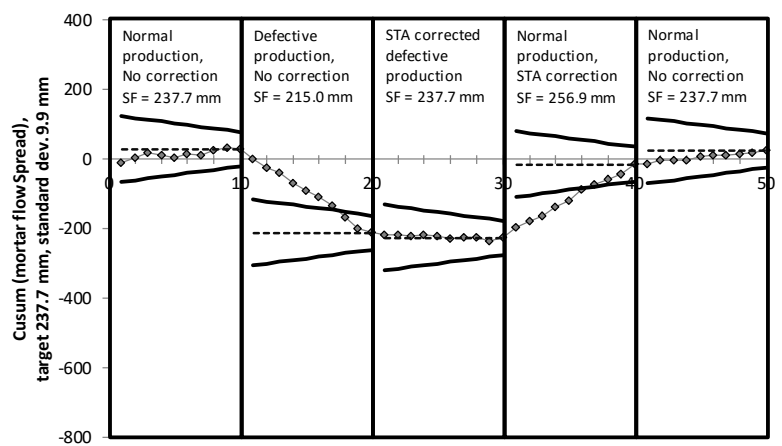

Fig. 2. Sample cusum + V-mask for $+10 \%$ cement betw. values 11 and 30 and corrective actions (PCE) betw. values 21 and 40.

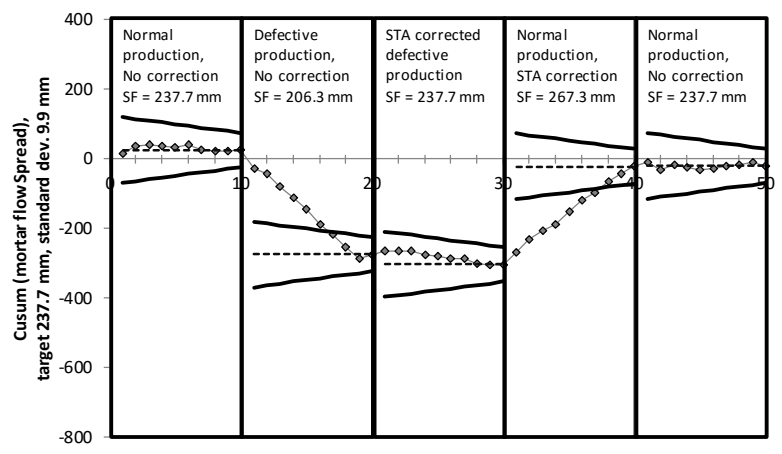

Fig. 3. Sample cusum + V-mask for $+10 \%$ LSF betw. values 11 and 30 and corrective actions (PCE) betw. values 21 and 40.

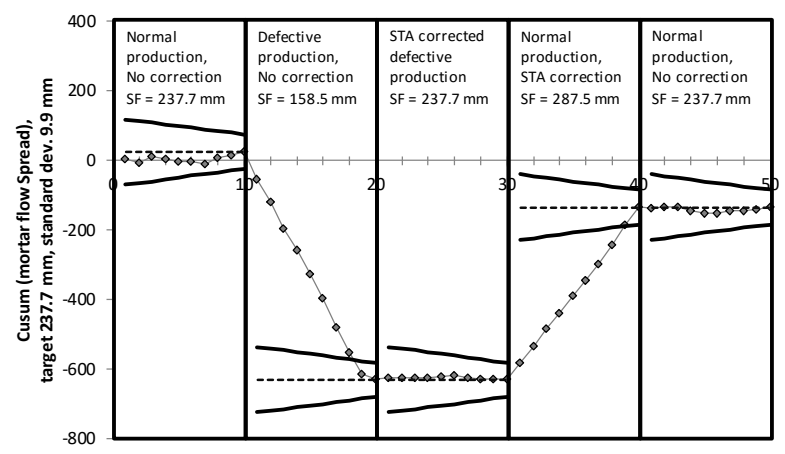

Fig. 4. Sample cusum + V-mask for $-10 \%$ water betw. values 11 and 30 and corrective actions (PCE) betw. values 21 and 40 .

All stiffening manipulations had a very strong effect on the rheological properties. Hence, the slope change of the cusum is quite strong in all cases. The strongest effect can be observed for $-10 \%$ water addition.

\subsection{Liquefying effects}

Exemplary data set plots for the liquefying manipulations are shown in Figs. 5-7. The liquefying effects are generally less pronounced than the stiffening effects. However, for less cement and less LSF, the cusum and V- mask clearly shows process changes clearly within the relevant periods. The effect of limestone filler was significantly more pronounced than the effect of cement. For the case of extra water (Fig. 7), the liquefying effect cannot be identified clearly by the standard truncated Vmask, although a prominent change of the slope is clearly visible. Therefore, for small effects as in the case of additional water addition, the standard truncated V-mask according to [17] might not be the best choice. And alternative V-masks should be observed.

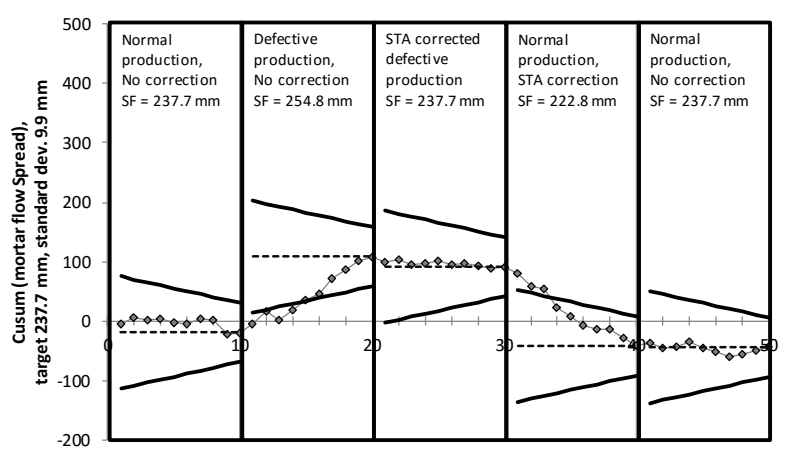

Fig. 5. Sample cusum + V-mask for $-10 \%$ cement betw. values 11 and 30 and corrective actions (STA) betw. values 21 and 40.

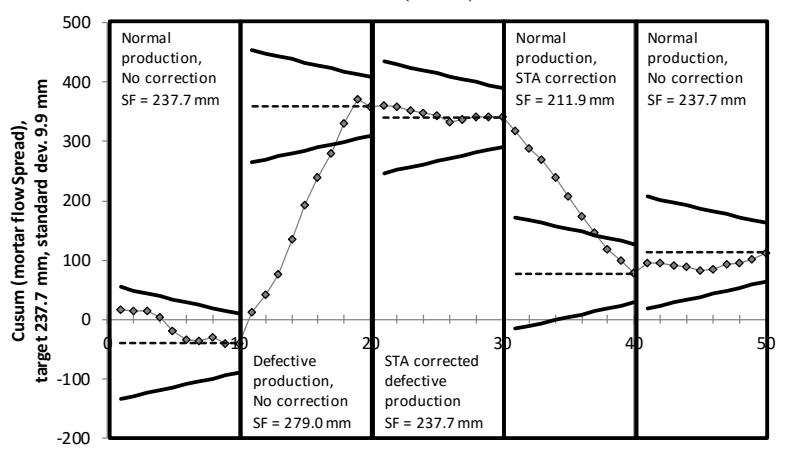

Fig. 6. Sample cusum + V-mask for $-10 \%$ LSF betw. values 11 and 30 and corrective actions (STA) betw. values 21 and 40 .

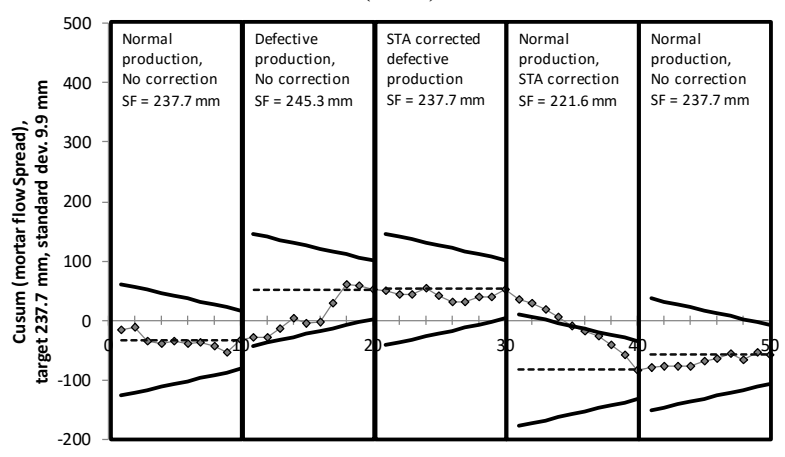

Fig. 7. Sample cusum + V-mask for $+10 \%$ water betw. values 11 and 30 and corrective actions (STA) betw. values 21 and 40 .

\subsection{Influence of decision interval and slope}

The Figs. 8-9 show cusum curves of the mean values of normally distributed random values with $+10 \%$ water addition between value 11 and 30 . However, different Vmask parameters are observed. Fig. 8 shows that decision intervals of $2.5 \sigma$ and $1 \sigma$ can clearly indicate the effect of supplementary water on the rheology clearly and effectively. 


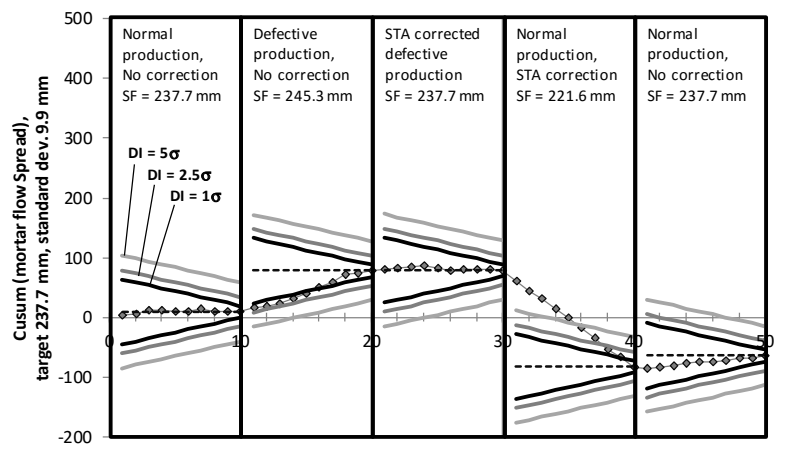

Fig. 8. Cusum of mean values of 10 random normally distributed cusum functions for $+10 \%$ water betw. values 11 and 30 and corrective actions (STA) betw. values 21 and 40 with different decision intervals (DI) for the V-mask.

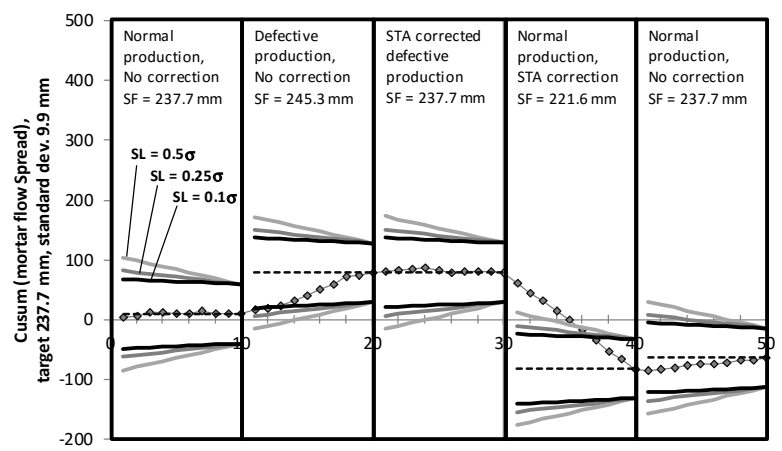

Fig. 9. Cusum of mean values of 10 random normally distributed cusum functions for $+10 \%$ water betw. values 11 and 30 and corrective actions (STA) betw. values 21 and 40 with different slopes (SL) for the V-mask.

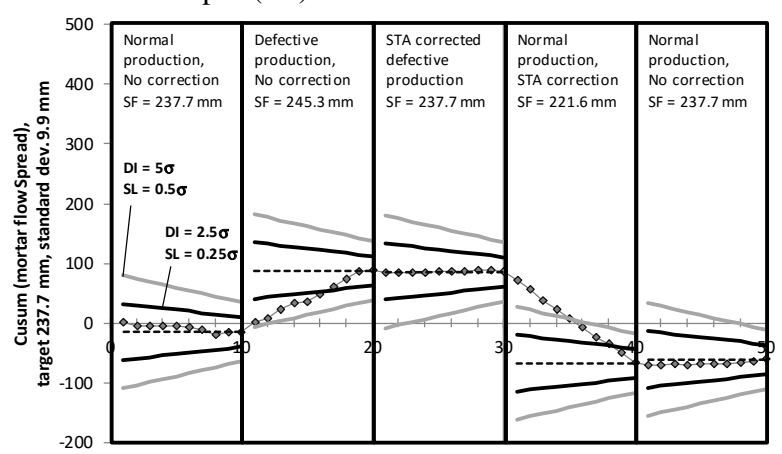

Fig. 10. Comparison of standard V-mask and optimised V-mask for a cusum of mean values of 10 random normally distributed cusum functions for $+10 \%$ water betw. values 11 and 30 and corrective actions (STA) betw. values 21 and 40

Fig. 9 shows the same situation for different slopes. A slope of $0.1 \mathrm{~s}$ would have identified the effect of the extra water on rheology also clearly, but compared to the effect of the decision interval, the effect is less pronounced.

The evaluation with an optimised V-mask with $\mathrm{DI}=2.5 \sigma$ and $\mathrm{SL}=0.25 \sigma$ is shown in Fig. 10 compared to the standard V-mask. The optimised V-mask reacts on changes very quick, so that process failures could be indicated already between the first 4-5 defective values. An even more rapid indication would be possible with a narrower $\mathrm{V}$-mask, but it has to be considered that the use of mean values for Figs. 8-10 causes less scatter for individual values. Therefore, a narrower V-mask would increase the risk that a normal production could be falsely interpreted as defective production.

\section{Summary and conclusions}

Today, robust process control becomes increasingly important for concrete manufacturing. Due to the complexity of concrete mixture compositions, it is difficult to identify root causes for process changes. However, with the use of superplasticizers and stabilising agents it is possible to control the rheology independent of the root cause.

A cusum data processing with $\mathrm{V}$-mask for decision making helps to identify systematic changes in processes rapidly. The results have shown that identification of systematic changes is possible with a standard V-mask, and that defective processes can be corrected effectively with PCE or STA. However, when the process is well understood, tailored V-mask parameters can help to minimise the reaction time. In the present case, a decision interval of $2.5 \sigma$ and a slope of $0.25 \sigma$ seemed to be ideal.

With increasing use of computational tools, perspectively it is possible to use the method for in-situ rheology control in complex automated processes such way, that rheology changes are identified in the beginning of the process using cusum and V-mask, so that still during the processing corrective actions can be taken so that at the final casting step the rheology fully achieves the target value.

\section{References}

[1] W. A. Shewhart, Economic control of quality of manufactured product. New York: Van Nostrand, 1931.

[2] E. L. Grandt and R. S. Leavenworth, Statistical Quality Control, 6 ed. New York, 1988.

[3] E. S. Page, "A Test for a Change in a Parameter Occurring at an Unknown Point," Biometrika, vol. 42, pp. 523-527, 1955.

[4] L. Dessolle, D. J. Biau, V. de Larouzière, C. Ravel, J.-M. Antoine, E. Daraï, and J. Mandelbaum, "Learning curve of vitrification assessed by cumulative summation test for learning curve (LCCUSUM)," Fertility and Sterility, vol. 92, pp. 943945, 9// 2009.

[5] D. J. Biau, S. M. Williams, M. M. Schlup, R. S. Nizard, and R. Porcher, "Quantitative and individualized assessment of the learning curve using LC-CUSUM," British Journal of Surgery, vol. 95, pp. 925-929, 2008.

[6] O. D. Aguirre Ospina, Á. M. Ríos Medina, M. Calderón Marulanda, and L. M. Gómez Buitrago, "Cumulative Sum learning curves (CUSUM) in basic anaesthesia procedures," Colombian Journal of Anesthesiology, vol. 42, pp. 142-153, 7// 2014.

[7] A. Young, J. P. Miller, and K. Azarow, "Establishing Learning Curves for Surgical Residents Using Cumulative Summation (CUSUM) Analysis," Current Surgery, vol. 62, pp. 330-334, 5// 2005.

[8] A. M. Parikh, A. M. Park, and J. Sumfest, "Cumulative summation (CUSUM) charts in the monitoring of hypospadias outcomes: A tool for 
quality improvement initiative," Journal of Pediatric Urology, vol. 10, pp. 306-311, 4// 2014.

[9] M. L. Sampson, V. Gounden, H. E. van Deventer, and A. T. Remaley, "CUSUM-Logistic Regression analysis for the rapid detection of errors in clinical laboratory test results," Clinical Biochemistry, vol. 49, pp. 201-207, 2// 2016.

[10] R. J. Novick, S. A. Fox, L. W. Stitt, T. L. Forbes, and S. Steiner, "Direct comparison of risk-adjusted and non-risk-adjusted CUSUM analyses of coronary artery bypass surgery outcomes," The Journal of Thoracic and Cardiovascular Surgery, vol. 132, pp. 386-391, 8// 2006.

[11] D. G. Pazhayamadom, C. J. Kelly, E. Rogan, and E. A. Codling, "Self-starting CUSUM approach for monitoring data poor fisheries," Fisheries Research, vol. 145, pp. 114-127, 8// 2013.

[12] D. G. Pazhayamadom, C. J. Kelly, E. Rogan, and E. A. Codling, "Decision Interval Cumulative Sum Harvest Control Rules (DI-CUSUM-HCR) for managing fisheries with limited historical information," Fisheries Research, vol. 171, pp. 154$169,11 / / 2015$.

[13] L. Qu, Z. Wu, M. B. C. Khoo, and P. Castagliola, "A CUSUM scheme for event monitoring," International Journal of Production Economics, vol. 145, pp. 268-280, 9// 2013.

[14] W. Schmidt, H.-C. Kühne, and F. Haamkens, "Shewhart- und CUSUM-Kontrollkarten zur gleichzeitigen Prozesssteuerung und Konformitätsbewertung - Neue Nachweisverfahren der Konformität in der zukünftigen EN 206," Betonund Stahlbetonbau, vol. 109, pp. 417-427, 2014.

[15] W. Schmidt and H.-C. Kühne, "Cusum control charts with V-mask in process control," CPI International, 2015.

[16] R. Caspeele and L. Taerwe, "Combined production and conformity control of concrete with acceptance cusum control charts," in Proceedings of the 7th International Probabilistic Workshop, Dresden, Germany, 2009.

[17] "BS 5703-2:2003, Guide to data analysis, quality control and improvement using cusum techniques Part 2: Introduction to decision-making using cusum techniques."

[18] "Monitoring concrete strength by the cusum system," The Concrete Institute, Midrand, South Africa2013.

[19] K. W. Day, "Economical control of concrete quality," Reprint from Australian Civil Engineering published via http://www.kenday.id.au/4.1-4.7.html, 1969.

[20] K. W. Day, "Quality Control of Concrete: Philosophy and Implementation," presented at the Seminar on Quality Control of Concrete, Hong Kong, 1980.

[21] K. W. Day, "Quality Control of 55 MPa Concrete for Collins Place Project, Melbourne, Australia," CONCRETE INTERNATIONAL, vol. 3, pp. 17-23, 1981.

[22] K. W. Day, Concrete Mix Design, Quality Control and Specification, 3 ed.: Taylor \& Francis, 2006.
[23] I. Gibb and T. Harrison, "Use of control charts in the production of concrete," ERMCO2010.

[24] W. Schmidt and H.-C. Kühne, "EN 206:2014: Cusum method or mean value criterion? / EN 206:2014: Kusum-Verfahren oder Mittelwertkriterium?," BFT international, vol. 80, pp. 24-31, 2014.

[25] M. Palacios, R. Flatt, F. Puertas, and A. SanchezHerencia, "Compatibility between Polycarboxylate and Viscosity-Modifying Admixtures in Cement Pastes," in 10th International Conference on Superplasticizers and Other Admixtures in Concrete, Prague, Czech Republic, 2012, pp. 29-40.

[26] R. Flatt and I. Schober, "Superplasticizers and the rheology of concrete," Understanding the Rheology of Concrete, pp. 144-208, 2012.

[27] R. J. Flatt, I. Schober, E. Raphael, E. Lesniewska, and C. Plassard, "Polymer Physics and Superplasticizers," in Ninth ACI International Conference on Superplasticizers and Other Chemical Admixtures in Concrete, Seville, Spain, 2009, pp. 113-122.

[28] D. Lowke and C. Gehlen, "Effect of Pore Solution Composition on Zeta Potential and Superplasticizer Adsorption," in Eleventh International Conference on Superplasticizers and Other Chemical Admixtures in Concrete, Ottawa, 2015, pp. 253-264.

[29] A. Zingg, F. Winnefeld, L. Holzer, J. Pakusch, S. Becker, and L. Gauckler, "Adsorption of polyelectrolytes and its influence on the rheology, zeta potential, and microstructure of various cement and hydrate phases," Journal of Colloid and Interface Science, vol. 323, pp. 301-312, 2008.

[30] J. Plank and B. Sachsenhauser, "Impact of Molecular Structure on Zeta Potential and Adsorbed Conformation of $\alpha$-Allyl- $\omega$-Methoxypolyethylene Glycol - Maleic Anhydride Superplasticizers," Journal of Advanced Concrete Technology, vol. 4, pp. 233-239, 2006.

[31] J. Plank and C. Hirsch, "Impact of zeta potential of early cement hydration phases on superplasticizer adsorption," Cement and Concrete Research, vol. 37, pp. 537-542, 2007.

[32] J. Stroh, M. C. Schlegel, W. Schmidt, Y. N. Thi, B. Meng, and F. Emmerling, "Time-resolved in situ investigation of Portland cement hydration influenced by chemical admixtures," Construction and Building Materials, vol. 106, pp. 18-26, Mar 1 2016.

[33] W. Schmidt, S. Peters, and H.-C. Kühne, "Effects of Particle Volume Fraction and Size on Polysaccharide Stabilizing Agents," in SP-302 Eleventh International Conference on Superplasticizers and Other Chemical Admixtures in Concrete, V. M. Malhotra, Ed., ed, 2015, pp. 3952.

[34] W. Schmidt, H. J. H. Brouwers, H.-C. Kühne, and B. Meng, "Influences of superplasticizer modification and mixture composition on the performance of self-compacting concrete at varied ambient temperatures," Cement and Concrete Composites, vol. 49, pp. 111-126, 2014. 